\title{
Online voltage estimation and control for smart distribution networks
}

\author{
RAGHAVENDRA $\mathbf{P}^{1}$, D. N. GAONKAR ${ }^{1}$
}

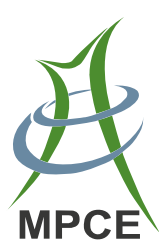

\begin{abstract}
The increasing deployment of Distributed Generation (DG) technologies introduces power quality challenges to the grid, in particular steady state voltage rise at the connection point for DG units. In most distribution networks, control and monitoring of grid parameters is missing, as well as system security is at risk. Smart grid technologies have the capability to realize the real-time measurements and on-load voltage controls. With the steady implementation of smart grid technologies throughout the existing distribution networks, the online voltage control can be achieved ensuring the power quality and voltage levels within the statutory limits. This study presents a methodology for the estimation of voltage profile in a smart distribution network with DG for the online voltage control, taking into account different line $X / R$ ratios and laterals. This method is based on maximum and minimum voltage estimation by remote terminal units (RTUs) placed only at DG connected bus and at capacitor connected bus. Voltage regulation is carried out based on RTUs estimated values. This work is tested on two radial distribution networks with/without DGs and laterals. Comparative results for voltage magnitudes estimated with different methodology are presented. The reported simulation results show that the method presented is capable of estimating the voltage profile along the distribution network
\end{abstract}

CrossCheck date: 18 November 2015

Received: 26 August 2015 / Accepted: 21 December 2015/Published online: 19 January 2016

(c) The Author(s) 2016. This article is published with open access at Springerlink.com

$\triangle$ RAGHAVENDRA P

raghudts@gmail.com

D. N. GAONKAR

dngaonkar@ieee.org

1 National Institute of Technology Karnataka (NITK), Surathkal, Mangalore, Karnataka 575025, India with DGs for the online voltage control, considering different line $X / R$ ratios and laterals.

Keywords Distributed generation, Power quality, Smart grid, Voltage rise

\section{Introduction}

Distributed generation (DG) installations are growing exponentially. The major driving forces of distributed generating systems are electricity market liberalization, developments in DG technologies and environmental concerns [1]. DG technologies offer a number of potential benefits in comparison to the conventional centralized systems [2-3]. Few of its benefits are lower capital cost, reduced high transmission and distribution losses, improved supply reliability and power management, reduced demand during peak times and better quality of power. While offering a numerous potential benefits, high penetration of DG units can cause several technical concerns [4-7]. Safety issues, thermal rating of equipment, power quality and reliability, system fault level, steady state voltage rise and system stability are the few factors that restrict the increasing penetration of DG systems. Steady state voltage rise at the connection point for DG units can be a bigger impediment to the growth of DG [6-8].

Traditional infrastructure of T\&D networks were originally built to deliver electricity to end-use customers from remotely generated at large-scale power plants. Distribution network operators have to ensure the customer voltages well within the tolerance limit. High DG penetration in the distribution network alters the network flows, greater variation in voltage which in turn adversely affecting the quality of supply. In most distribution networks, control and monitoring of grid parameters are missing, as well as 
system security is at risk. The introduction of smart grid technologies will address these issues. With the study implementation of smart grid technologies in the existing distribution networks, real time measurement and online control of voltage can be achieved [9-10]. Voltage profile has to be estimated first for the voltage control.

Voltage profile estimation technique with limited number of measuring points is presented in [11]. New scheme for voltage profile estimation in distribution network for the online voltage control is proposed in [12]. Based on the voltages and currents measurements at the heads of feeder, the other nodal voltages are estimated. A global parameter method for voltage drop estimation in distribution system is proposed in [13]. This method is based on the equivalent line which is determined by length and section of network lines. However, these methods are not considering any power injections from DGs or capacitors banks at any point in the network.

A coordinated voltage control scheme for real time implementation in distribution networks with DG is proposed in [14]. This scheme is based on voltage estimations by remote terminal units placed at DG and capacitor buses. An amendable control scheme for the above technique is proposed in [15]. The proposed scheme needs less parameters measurements which reduces communication and calculation burden on remote terminal units (RTUs). These schemes assumes that line impedance of any section is constant. However, in general, $R / X$ ratios are not constant along the line. Also, these schemes are not well covered the distribution systems with laterals.

This paper presents a methodology for the estimation of voltage profile in a smart distribution network with DG for the online voltage control. The presented method estimates the voltages of distribution network characterized by radial configuration of different line $X / R$ ratios and laterals. This method is based on maximum and minimum voltage estimation by RTUs placed only at DG/capacitor connected bus and laterals node point. Based on the readings of these RTUs, online voltage control can be achieved. This work is tested on two radial distribution networks. Obtained results for voltage magnitudes estimated are compared with backward/forward sweep load flow methods reported in [16-19]. The simulated results using the above method are presented in this paper, taking into account different line $X / R$ ratios and laterals with DG systems. The reported results show that the method presented is capable of estimating the voltage profile along the distribution network with DGs for the online voltage control.

\section{Impact of DG on voltage rise}

Integration of DG units into the traditional distribution model for the grid causes power flows in two directions resulting greater variation in voltage. These effects will be accountable due to the small $(X / R)$ ratio of distribution network lines. Two-bus distribution system connected with DG is show in Fig. 1.

The voltage rise can be calculated from the analysis of two-bus distribution system as shown in Fig. 1. The magnitude of voltage rise is approximately given by:

$\Delta V=V_{\mathrm{G}}-V_{\mathrm{S}} \approx R\left(P_{\mathrm{G}}-P_{\mathrm{L}}\right)+X\left( \pm Q_{\mathrm{G}}-Q_{\mathrm{L}}\right)$

where $V_{\mathrm{G}}$ and $V_{\mathrm{S}}$ are voltages of DG connected bus and station bus respectively; $P_{\mathrm{G}}, Q_{\mathrm{G}}$ DGs active and reactive power injections; $P_{\mathrm{L}}, Q_{\mathrm{L}}$ loads active and reactive power consumptions; and $R, X$ lines resistance and reactance respectively. It is clear that the amount of voltage rise on a distribution network with DGs depends on the amount of active power injected by the DGs. If the voltage rise issue is alleviated, then DGs with higher capacities are allowed to connect on distribution networks.

\section{Voltage estimation and structure of RTU}

\subsection{Voltage estimation}

Based on the results in [14], in general, the maximum voltage values arise only at DG or capacitor connected buses and at the substation bus. The author suggested to install RTU at each of these buses. RTUs connected at these points can directly read the node voltages for maximum voltage values. In case of minimum voltage values, possibility of occurrence is only at the end nodes of the feeder or in-between any two DG (or capacitors, as well as between a capacitor and DG) connected buses. Voltage of the end bus can read directly from the RTU connected at this point or it can be estimated. This method assumes that the load is concentrated mid-way between two DG units.

From Fig. 2 based on the above assumptions, the value of minimum voltage between two DG units, calculated by $D G_{1}$ is given as:

$V_{\mathrm{est}, D G_{1}}=V_{1}-\left(P_{1} \frac{r}{2}+Q_{1} \frac{x}{2}\right)$

Also, the value of the minimum voltage point calculated by $D G_{2}$ is given as:

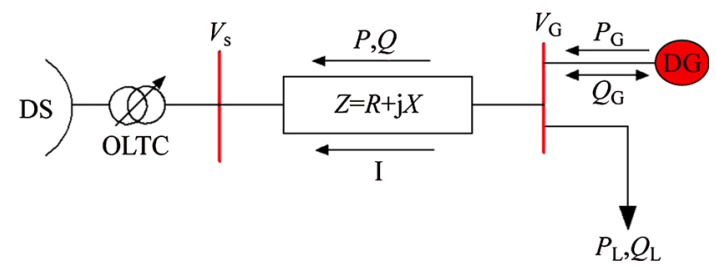

Fig. 1 Two-bus distribution system connected with DG 


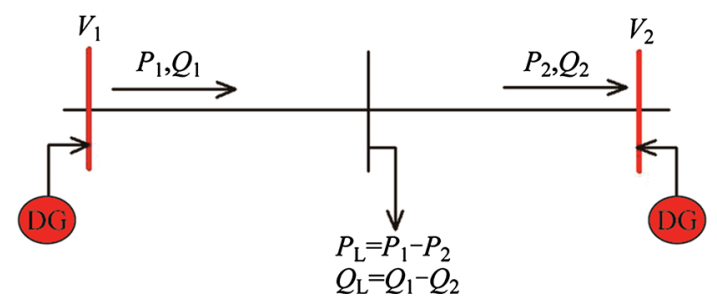

Fig. 2 Small section of a distribution system

$V_{\mathrm{est}, D G_{2}}=V_{2}+\left(P_{2} \frac{r}{2}+Q_{2} \frac{x}{2}\right)$

A better estimation is achieved by averaging these two values:

$V_{\mathrm{est}}=\frac{V_{\mathrm{est}, D G_{1}}+V_{\mathrm{est}, D G_{2}}}{2}$

where $V_{\text {est }}$ is the estimated minimum value of voltage between $D G_{1}$ and $D G_{2}$.

\subsection{RTU system structure}

System structure of RTUs is shown in Fig. 3. This paper assumes that the communication infrastructure is widespread along the distribution network. The system consists of an RTU at each DG, each line capacitor and at each laterals node point. Communication link between RTUs that have a power line connection is shown in dotted lines. However, the implementation of the reported online voltage control is possible in every conventional distribution system equipped with RTUs at DGs or capacitor buses as well as overlaying communication network. Each RTU has to take few measurements and perform calculations. Figure 4 show the parameters measured by each RTU. Unlike the model proposed in [14], the measurement of voltage of the immediate neighbor buses is not needed. Therefore, the number of measurement and calculation burden on each RTU reduced [15]. The function of the each RTU is to report maximum and minimum voltages to its neighbor RTU.

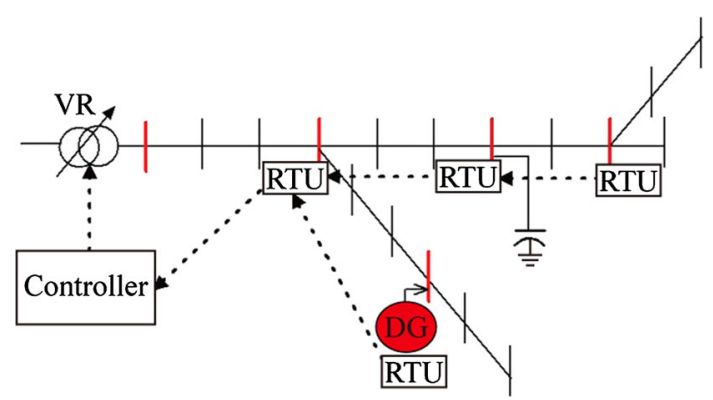

Fig. 3 System structure of RTU

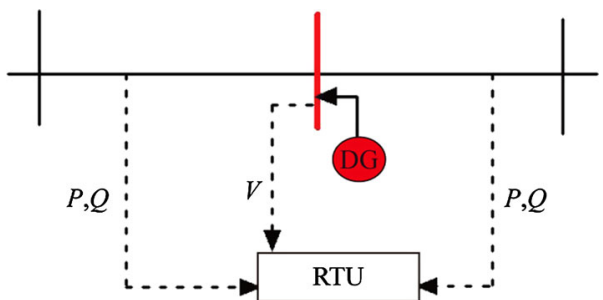

Fig. 4 Details of RTU measurements

The reported method has been designed to be active in every unpredictable events such as component failure, power outages or unpredictable change in DGs output. As the reported method is a real time voltage control model, the effect of unpredictable change in DGs output or load variation on distribution system is considered in this model. While voltage at some buses change due to variation in DGs output and load changes, the real time voltage control method first senses this situation and then decides to change tap position of the voltage regulation in order to keep the system voltage within the permissible range. Let RTU $n$ be the RTU connected at $n^{\text {th }}$ bus where DG/capacitor/lateral node point is connected. Defining RTU $n+1$ and RTUn-1 upstream and downstream RTUs connected at $n+1$ and $n-1$ nodes respectively. The flow chart reported in [15] shows the calculation process of RTU. The furthest DG RTU that is $\mathrm{RTU}_{n+1}$, assumes that the maximum voltage value of the feeder equals to its own DG bus voltage, then it estimates the minimum voltage value and reports to upstream $\mathrm{RTU}_{n}$. Immediately, after receiving these data from downstream $\mathrm{RTU}_{n+1}, \mathrm{RTU}_{n}$ will check if its own DG connected voltage is greater than the downstream voltage and updates the maximum value. $\mathrm{RTU}_{n}$ will estimate the minimum value, compares with downstream and updates the minimum value. This process will continue from furthest RTU till the station bus. Each RTU updates the maximum and minimum voltage values to its neighbor. After receiving these values from each feeder, voltage regulator will decide absolute maximum and minimum voltage values. Voltage regulator will alter its tap settings based on these values. Regulator will raise its tap position, if the system voltage is less than the permissible voltage and reduces its tap position if system voltage greater than permissible voltage. Before proceeding for voltage regulation of the feeder, the basic condition has to be verified in order for the voltage regulator controller to find a suitable tap, which is given as:

$V_{\text {max,feeders }}-V_{\min , \text { feeders }}<V_{\text {max,perm }}-V_{\text {min,perm }}$

where $V_{\text {max,feeders }}$ and $V_{\text {min,feeders }}$ are the absolute maximum and minimum voltage of the system; and $V_{\text {max,perm }}$ and $V_{\text {min,perm }}$ the permissible maximum and minimum voltage of the system respectively. If the equation does not hold 
then one regulator cannot handle the voltage regulation of the whole system. In such situation, it is recommended to install more voltage regulators in the system [14]. Based on the estimated maximum and minimum values, the voltage regulator will calculate a suitable tap position accordingly using (6) which is reported in [15].

$$
\begin{aligned}
\operatorname{Tap}_{\text {new }}= & \text { Tap }_{\text {old }} \\
& +\left[\frac{\left(1+\frac{V_{\text {max,feders }}-V_{\text {min,feders }}}{2}\right)-V_{\text {max,feeders }}}{\text { Step }}\right]
\end{aligned}
$$

where $T a p_{\text {new }}$ and $T a p_{\text {old }}$ are new tap and initial tap position respectively; and Step is step change value of voltage regulator.

\section{Simulation results}

In this section, simulation results of the test systems are reported. This work is tested on two radial distribution systems. For all the cases, the following data is assumed. The upper voltage limit is 1.05 p.u.; The lower voltage limit is 0.95 p.u.; The number of taps is 32; Step change/tap ratio is 0.00625 p.u..

\subsection{Case study 1: 12-bus radial distribution system with DGs}

First test case is a 12-bus radial distribution system with DGs connection as shown in Fig. 5. Two DGs are connected to bus 6 and 10. The details of the line and load data are given in [20].

In order for the RTUs to estimate the voltage profile of the system, RTUs are connected at DG connected bus points (RTUs at nodes 6 and 10). These RTUs connection are indicated by thick dark red lines in Fig. 5. For the comparison purpose, the system is parted into different sections shown in Fig. 5. The voltage profile of the system generated based on load flow solution and based on the readings of the RTUs connected at two DGs is shown in Fig. 6. Table 1 gives the comparison of voltage profile values estimated by backward/forward load flow method and based on RTUs reading. From the table it is clear that global values of maximum and minimum voltages estimated by RTUs are almost matching with load flow values.

Figure 6 shows that minimum voltage of the feeder is about 0.9360 per unit and violates the lower voltage limit of the system. In order to correct the voltage profile of the system, voltage regulator will change its tap setting. Figure 7 shows voltage profile of the system before and after the voltage regulation. Voltage regulator raised its tap

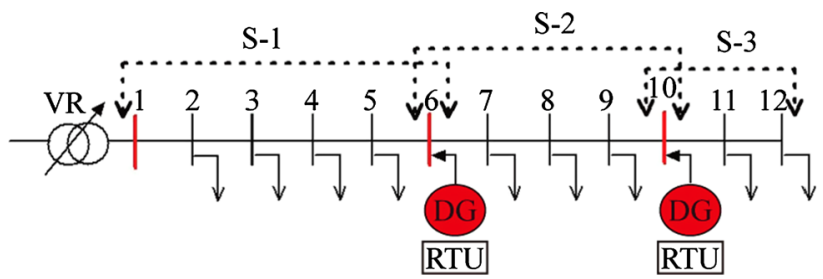

Fig. 5 12-bus radial distribution system with DGs connection

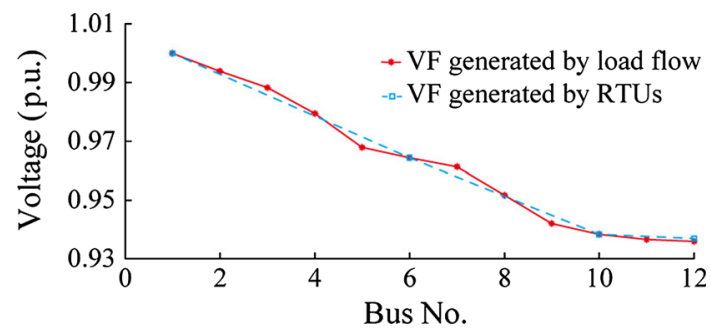

Fig. 6 Voltage profile generated by load flow method versus RTUs method

setting to tap number 5 and this raises regulator voltage to 1.03125 p.u..

\subsection{Case study 2(a): 69-bus distribution system with laterals}

In this case, 69-bus distribution system with laterals is considered for the study as shown in Fig. 8. The rated line voltage of the system is $12.66 \mathrm{kV}$. The line and load data of the system is given in [21, 22].

The system consists of seven laterals originating at six different lateral node points. Hence, in order for the RTUs to estimation the voltage profile of the system, a minimum of six numbers of RTUs has to be connected at lateral originating node points. Also, in the case of long feeders without any laterals and DGs (or capacitors) in-between, It is recommended to connect RTUs at the end-node of the feeder for accurate estimation. In this particular system, Six RTUs are connected at laterals node points (RTUs at nodes $3,4,8,9,11,12$ ) plus two RTUs at end-node feeders (RTUs at node 27, 65). These RTUs connections are indicated by thick dark red node bus in Fig. 8. Also, system is partitioned into different sections $(\mathrm{S}-1, \mathrm{~S}-2, \ldots)$ for comparison as shown in the figure. Voltage profile generated by load flow analysis versus readings of RTU is plotted in Fig. 9. Table 2 compares voltage values estimated based on backward/forward sweep load flow method and based on RTUs reading.

Figure 9 shows that the minimum voltage of the system is about 0.9092 p.u., which violates the lower voltage limit of the system. In order to correct the voltage profile of the system voltage regulator will change its tap setting. 
Table 1 Voltage values estimated by load flow method and based on RTUs readings (p.u.)

\begin{tabular}{lllrl}
\hline & \multicolumn{2}{l}{ Backward/forward load flow method } & \multicolumn{2}{c}{ RTUs method } \\
\cline { 2 - 5 } & $V_{\max }$ & $V_{\min }$ & $V_{\max }$ & 1.0000 \\
S-1 & 1.0000 & 0.9680 & 0.9643 & 0.9779 \\
S-2 & 0.9643 & 0.9421 & 0.9384 & 0.9459 \\
S-3 & 0.9384 & 0.9359 & 1.0000 & 0.9370 \\
Global values & 1.0000 & 0.9351 & 0.9370 \\
\hline
\end{tabular}

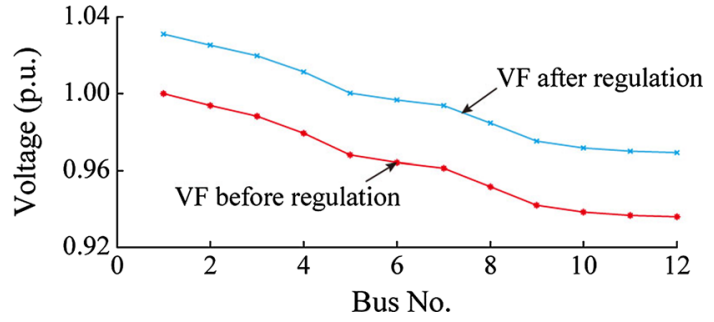

Fig. 7 Voltage profile of the system before and after regulation

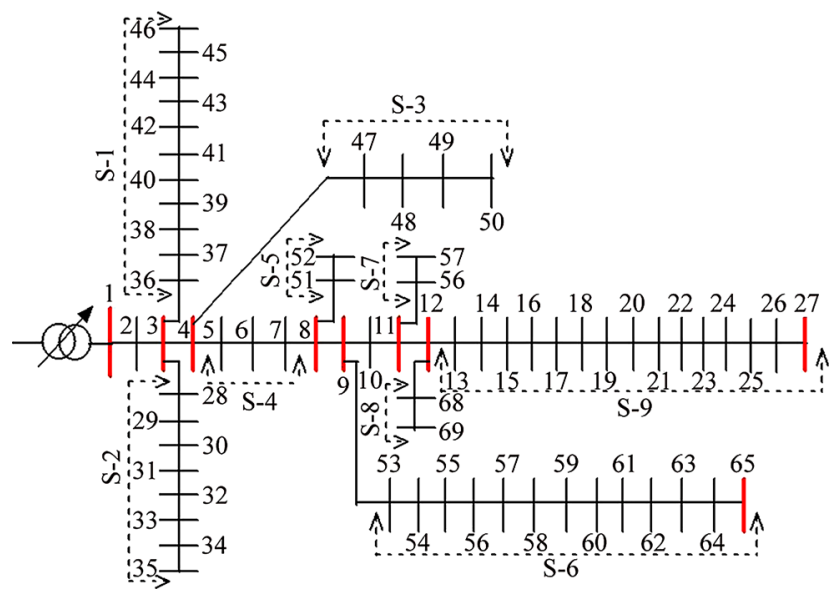

Fig. 8 69-bus distribution system with laterals

Figure 10 shows voltage profile of the system before and after the voltage regulation. Voltage regulator raised its tap setting to tap number 7 and this raises regulator voltage to 1.0437 p.u..

\subsection{Case study 2(b): 69-bus distribution system with DGs and laterals}

In this case, system with DGs connection is considered. Voltage regulator output is set at 1.0437 p.u.. Two DGs of capacity $2 \mathrm{MW}$ and $1 \mathrm{MW}$ are connected at nodes 19 and 60 respectively. In order for the RTUs to estimate the voltage profile of the system, Two RTUs are connected at DGs node points (RTUs at nodes 19,60) and six RTUs are connected at laterals node points (RTUs at nodes 3, 4, 8, 9,

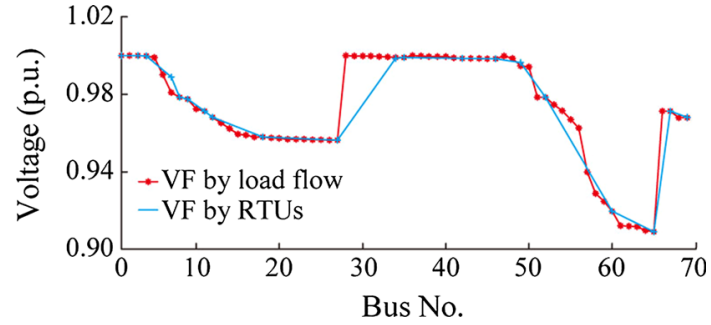

Fig. 9 Voltage profile generated by load flow method versus RTUs method

Table 2 Voltage values estimated by load flow method and based on RTUs readings (p.u.)

\begin{tabular}{llllll}
\hline & \multicolumn{2}{l}{$\begin{array}{l}\text { Backward/forward load flow } \\
\text { method }\end{array}$} & & \multicolumn{2}{l}{ RTUs method } \\
\cline { 2 - 3 } & $V_{\max }$ & $V_{\min }$ & & $V_{\max }$ & $V_{\min }$ \\
\hline S-1 & 0.9999 & 0.9984 & & 0.9999 & 0.9984 \\
S-2 & 0.9999 & 0.9990 & & 0.9999 & 0.9982 \\
S-3 & 0.9999 & 0.9942 & & 0.9999 & 0.9965 \\
S-4 & 0.9999 & 0.9808 & & 0.9999 & 0.9890 \\
S-5 & 0.9786 & 0.9785 & & 0.9786 & 0.9786 \\
S-6 & 0.9774 & 0.9092 & & 0.9774 & 0.9092 \\
S-7 & 0.9713 & 0.9713 & & 0.9713 & 0.9713 \\
S-8 & 0.9682 & 0.9678 & & 0.9682 & 0.9680 \\
S-9 & 0.9682 & 0.9563 & & 0.9682 & 0.9563 \\
Global values & 0.9999 & 0.9092 & & 0.9999 & 0.9092 \\
\hline
\end{tabular}

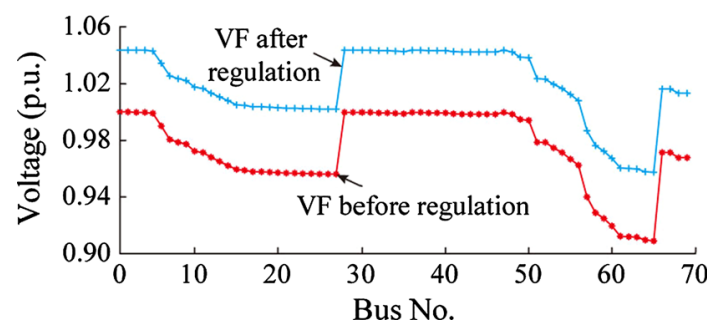

Fig. 10 Voltage profile of the system before and after regulation

11, 12). These RTUs connections are indicated by thick dark red node bus in Fig. 11. Also, system is partitioned into different sections $(\mathrm{S}-1, \mathrm{~S}-2, \ldots)$ for the sake of 


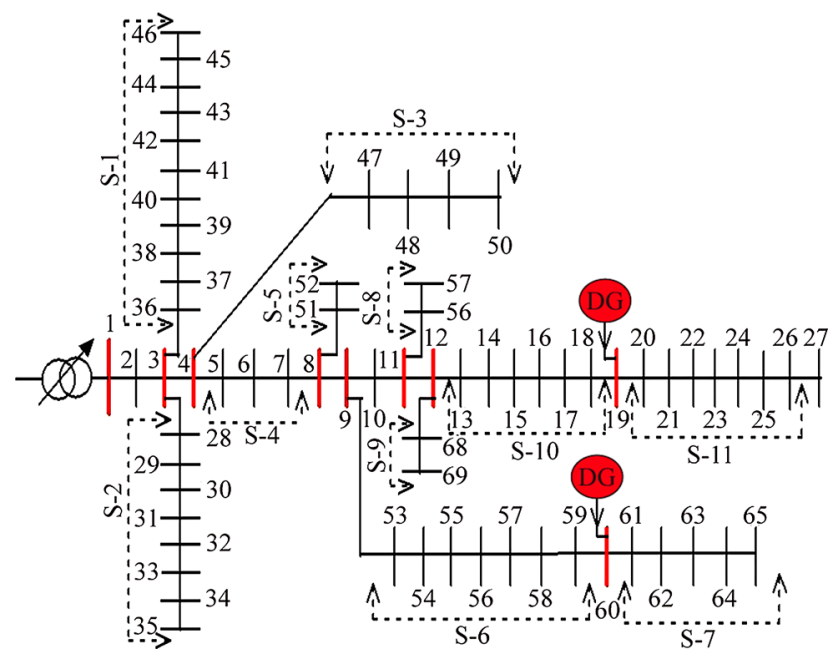

Fig. 11 69-bus distribution system with DGs and laterals

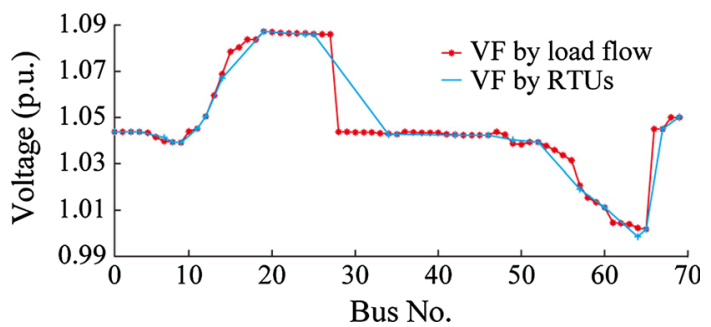

Fig. 12 Voltage profile generated by load flow method versus RTUs method

Table 3 Voltage values estimated by load flow method and based on RTUs readings (p.u.)

\begin{tabular}{llllll}
\hline & \multicolumn{2}{l}{$\begin{array}{l}\text { Backward/forward load flow } \\
\text { method }\end{array}$} & & \multicolumn{2}{l}{ RTUs method } \\
\cline { 2 - 3 } \cline { 6 - 7 } & $V_{\max }$ & $V_{\min }$ & & $V_{\max }$ & $V_{\min }$ \\
\hline S-1 & 1.0436 & 1.0422 & & 1.0436 & 1.0421 \\
S-2 & 1.0436 & 1.0427 & & 1.0436 & 1.0419 \\
S-3 & 1.0436 & 1.0382 & & 1.0436 & 1.0402 \\
S-4 & 1.0436 & 1.0396 & & 1.0436 & 1.0413 \\
S-5 & 1.0392 & 1.0392 & & 1.0392 & 1.0392 \\
S-6 & 1.0390 & 1.0134 & & 1.0390 & 1.0189 \\
S-7 & 1.0112 & 1.0016 & & 1.0112 & 0.9983 \\
S-8 & 1.0450 & 1.0449 & & 1.0450 & 1.0449 \\
S-9 & 1.0502 & 1.0499 & & 1.0502 & 1.0501 \\
S-10 & 1.0837 & 1.0502 & & 1.0502 & 1.0668 \\
S-11 & 1.0871 & 1.0859 & & 1.0871 & 1.0855 \\
Global values & 1.0871 & 1.0016 & 1.0871 & 0.9983 \\
\hline
\end{tabular}

comparison as shown in figure. Voltage profile generated by load flow analysis versus readings of RTU is plotted in Fig. 12. Table 3 compares voltage values estimated based

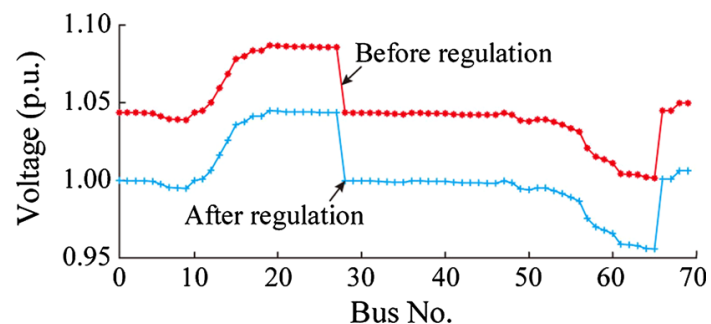

Fig. 13 Voltage profile of the system before and after regulation

on backward/forward sweep load flow method and based on RTUs reading. It is clear that global values of maximum and minimum voltages estimated by RTUs are almost matching with load flow values.

Figure 12 shows that the maximum voltage of the system is about 1.0871 p.u., which violates the upper voltage limit of the system. In order to correct the voltage profile of the system voltage regulator will decrease its tap setting. Figure 13 shows voltage profile of the system before and after the voltage regulation. Voltage regulator decreased its tap setting to tap number 0 from earlier tap number 7 , and this decreases regulator voltage to 1.0 p.u. In case tap settings are reduced further voltage at 65 node violets the lower voltage limit of the system.

\section{Conclusion}

A methodology for the estimation of voltage profile in a smart distribution network with DG for the online voltage control considering different line $X / R$ ratios and laterals is presented. This method is based on maximum and minimum voltage estimation by RTUs placed only at DG connected bus and capacitor connected bus. This method reduces the number of monitoring points by connecting RTUs only at DG/capacitor node and laterals node point. This is a great advantage as there is no need to monitor all the system buses. This work is tested on two radial distribution networks. Comparative results show that RTUs estimated values are almost matching with backward/forward sweep load flow method. The reported simulation results show that the method presented is capable of estimating the voltage profile along the distribution network with DGs for the online voltage control.

Open Access This article is distributed under the terms of the Creative Commons Attribution 4.0 International License (http:// creativecommons.org/licenses/by/4.0/), which permits unrestricted use, distribution, and reproduction in any medium, provided you give appropriate credit to the original author(s) and the source, provide a link to the Creative Commons license, and indicate if changes were made. 


\section{References}

[1] Peças Lopes JA, Hatziargyriou N, Mutale J et al (2007) Integrating distributed generation into electric power systems: a review of drivers, challenges and opportunities. Electr Power Syst Res 77(9):1189-1203

[2] Pepermans G, Driesen J, Haeseldonckx D et al (2005) Distributed generation: definition, benefits and issues. Energy Policy 33(6):787-798

[3] El-Khattam W, Salama MMA (2004) Distributed generation technologies, definitions and benefits. Electr Power Syst Res 71(2):119-128

[4] Ackermann T, Knyazkin V (2002) Interaction between distributed generation and the distribution network: operation aspects. In: Proceedings of the IEEE/PES transmission and distribution conference and exhibition 2002: Asia and Pacific, vol 2, Yokohama, 6-10 Oct 2002, pp 1357-1362

[5] Jenkins N, Strbac G (1995) Effects of small embedded generation on power quality. In: Proceedings of the IEE colloquium on issues in power quality, Coventry, 28 Nov 1995, pp 6/1-6/4

[6] Barker PP, de Mello RW (2000) Determining the impact of distributed generation on power systems, Part 1: radial distribution systems. In: Proceedings of the power engineering society summer meeting, vol 3, Seattle, 16-20 Jul 2000, pp $1645-1656$

[7] Masters CL (2002) Voltage rise: the big issue when connecting embedded generation to long $11 \mathrm{kV}$ overhead lines. Power Eng J 16(1):5-12

[8] Jenkins N (1995) Embedded generation. Power Eng J 9(3): $145-150$

[9] Aguero JR (2012) Applications of smart grid technologies on power distribution systems. In: Proceedings of the 2012 IEEE PES innovative smart grid technologies (ISGT'12), Washington, DC, 16-20 Jan 2012, 1 pp

[10] Rugthaicharoencheep N, Boonthienthong M (2012) Smart grid for energy management on distribution system with distributed generation. In: Proceedings of the 2012 IEEE international conference on cyber technology in automation, control, and intelligent systems (CYBER'12), Bangkok, 27-31 May 2012, pp 165-169

[11] Chessmore DT, Lee WJ, Muston WE et al (2009) Voltageprofile estimation and control of a distribution feeder. IEEE Trans Ind Appl 45(4):1467-1474

[12] Hiyama T, Matsumoto Y, Nagaie S (2005) On-line estimation and control of voltage profile along $6.6 \mathrm{kV}$ feeders. In: Proceedings of the 2005 IEEE/PES transmission and distribution conference and exposition: Asia and Pacific, Dalian, China, 15-17 Aug 2005, 5 pp

[13] Vujosevic I, Spahic E, Rakocevic D (2002) One method for the estimation of voltage drop in distribution systems. In: Proceedings of the 2002 IEEE power engineering society summer meeting, vol 1, Chicago, 21-25 July 2002, pp 566-569
[14] Elkhatib ME, El-Shatshat R, Salama MMA (2011) Novel coordinated voltage control for smart distribution networks with DG. IEEE Trans Smart Grid 2(4):598-605

[15] Homaee O, Zakariazadeh A, Jadid S (2012) Online voltage control approach in smart distribution system with renewable distributed generation. In: Proceedings of the 2nd Iranian conference on smart grids (ICSG'12), Tehran, 24-25 May 2012, 6 $\mathrm{pp}$

[16] Shirmohammadi D, Hong HW, Semlyen A et al (1988) A compensation-based power flow method for weakly meshed distribution and transmission networks. IEEE Trans Power Syst 3(2):753-762

[17] Augugliaro A, Dusonchet L, Favuzza S et al (2008) A new backward/forward method for solving radial distribution networks with PV nodes. Electr Power Syst Res 78(3):330-336

[18] Bompard E, Carpaneto E, Chicco G et al (2000) Convergence of the backward/forward sweep method for the load-flow analysis of radial distribution systems. Int J Electr Power Energy Syst 22(7):521-530

[19] Chang GW, Chu SY, Wang HL (2007) An improved backward/forward sweep load flow algorithm for radial distribution systems. IEEE Trans Power Syst 22(2):882-884

[20] Das D, Nagi HS, Kothari DP (1994) Novel method for solving radial distribution networks. IEE P-Gener Transm Distrib 141(4):291-298

[21] Abdellatif H, Zehar K (2006) Efficient load flow method for radial distribution feeders. J Appl Sci 6(13):2741-2748

[22] Yammani C, Maheswarapu S, Matam S (2011) Enhancement of voltage profile and loss minimization in distribution systems using optimal placement and sizing of power system modeled DGs. J Electr Syst 7(4):448-457

RAGHAVENDRA $P$ is currently working toward the Ph.D. degree in the Department of Electrical \& Electronics Engineering, National Institute of Technology Karnataka (NITK), Surathkal, India. His research interests include voltage control for distribution systems, distributed generation systems and smart grids.

D. N. GAONKAR received the Ph.D. degree from Indian Institute of Technology, Roorkee, India in the year 2008. He was a visiting scholar at the University of Saskatchewan Canada. He visited the Center for Future Energy Systems (CFES) at Rensselaer Polytechnic Institute (RPI), Troy New York for research interaction. Currently, he is working as a faculty in the Department of Electrical Engineering, National Institute of Technology Karnataka (NITK), Surathkal, India. His research interests include power system operation and control, distributed generation systems and power electronics. 